\title{
Desigualdades no interior da escola: a formação da turma dos repetentes
}

\author{
Inequalities inside the school: \\ the formation of the repeating students classroom \\ Desigualdades en el interior de la escuela: \\ la formación de la clase de repitentes
}

FREDERICO ALVES ALMEIDA

https://orcid.org/0000-0002-9044-6668

Universidade Federal de Minas Gerais

Faculdade de Educação

Departamento de Cências Aplicadas à Educação

Belo Horizonte, MG, Brasil

FLAVIA PEREIRA XAVIER

https://orcid.org/0000-0002-8609-2756

Universidade Federal de Minas Gerais

Faculdade de Educação

Departamento de Cências Aplicadas à Educação

Belo Horizonte, MG, Brasil

\begin{abstract}
Resumo: O objetivo desta pesquisa é analisar o processo de formação de turmas em escolas de ensino fundamental. Utilizamos dados coletados pela Prova Brasil e Censo Escolar de escolas municipais de Contagem-MG, considerando sexo, cor, nível socioeconômico, desempenho em Matemática e repetência. Os resultados apontam que alunos já retidos, com baixo nível socioeconômico e desempenho insuficiente estavam concentrados em salas específicas, e que o agrupamento dos estudantes por tais características foi uma decisão da escola, ainda que pesquisas demonstrem as desvantagens dessa forma de organização.
\end{abstract}

Palavras-chave: Repetência. Composição das turmas. Escolas públicas. Desigualdades escolares.

Abstract: The objective of the research is to analyze the formation process of elementary school classrooms. The paper uses data from School Census and 'Prova Brasil' of municipal schools of Contagem-MG, considering gender, race, socioeconomic status, performance in Mathematics, and grade retention. The results show that the students who experienced grade retention, with low socioeconomic status and insufficient performance, were concentrated in specific classrooms, and grouping of students by certain characteristics was a school decision, although researches show the disadvantages of this form of organization.

Keywords: Grade retention. Classroom composition. Public schools. School inequalities. 
Resumen: El objetivo de la investigación es analizar el proceso de formación de las clases en una serie de escuelas de enseñanza primaria. Utilizamos datos recopilados por Prova Brasily por el Censo Escolar de escuelas del municipio de Contagem-MG, considerando el género, color, nivel socioeconómico, rendimiento en Matemáticas y la repetición. Los resultados muestran que estudiantes que ya ban reprobado, bajo nivel socioeconómico y bajo rendimiento se concentraron en clases especificas, y que agrupar a los estudiantes por ciertas características fue una decisión de la escuela, a pesar de que la investigación muestra las desventajas de esa forma de organización.

Palabras clave: Repitencia. Composición de las clases. Escuelas públicas. Desigualdades escolares.

\section{INTRODUÇÃO}

É comum os indivíduos associarem as possibilidades de mobilidade social, isto é, as chances de ascensão e realização da vida ao aumento da escolarização formal. No entanto, a Sociologia tem demonstrado que o sucesso escolar ainda é fortemente ligado às origens sociais dos estudantes e que a escola nem sempre é capaz de promover a redução das desigualdades esperadas, quando não as reproduz (ALVES; SOARES; XAVIER, 2016; BRITO, 2017; SOARES; DELGADO, 2016). As desigualdades podem, inclusive, acontecer dentro das escolas, segregando os estudantes e reduzindo as oportunidades escolares de determinados grupos (ALVES et al, 2016; BARTHOLO; COSTA, 2014).

Partindo disso, o trabalho analisa a alocação de alunos nos diferentes turnos e turmas de uma amostra de escolas, considerando: (1) sua situação de repetência; (2) se características adscritivas (sexo e cor) e socioeconômicas podem influenciar a formação das turmas; (3) o desempenho escolar, medido pela proficiência em Matemática; e (4) a opção consciente das gestões escolares nos procedimentos de enturmação dos alunos. As duas próximas seções apresentam uma abordagem teórica das desigualdades escolares, seguida da descrição metodológica da pesquisa e da análise dos seus resultados. Por fim, são discutidos os possíveis impactos de tal prática na qualidade da educação.

\section{RELAÇÃO ENTRE ESCOLARIDADE E AS DESIGUALDADES SOCIAIS}

Indivíduos se distribuem em diferentes posições, com diferentes funções e ocupações, definidas por relações de poder, de prestígio, hierarquia ou recompensas desiguais, que geram também posições sociais desiguais, mais ou menos estratificadas. Os estudos sobre estratificação e mobilidade, dentro das 
Ciências Sociais, procuram compreender as formas de preenchimento dessas posições, bem como mecanismos e motivações que limitam ou possibilitam a mobilidade (DAVIS; MOORE, 1969; HALLER, 2014).

A sociedade moderna, especialmente, tem assumido que seus membros não devem definir a posição social pela herança ou pelo sangue, mas conquistá-la por sua capacidade e esforço próprio, o mérito. Nesse sentido, a educação escolar é idealizada como um dos principais meios de mobilidade social, já que a ocupação social e profissional dos indivíduos irá depender do grau de educação formal que alcançaram. Isto é, ela tem sido percebida como uma forma, talvez a mais próxima, de os indivíduos transitarem de uma posição social inferior para outra mais elevada, ainda que pesem fortemente as suas origens sociais (RIBEIRO, 2007). As pessoas esperam esse efeito da escolarização: investem tempo e recursos na aquisição de conhecimento, associando o aumento de escolaridade ao aumento na renda; mantêm expectativas de que os governos priorizarão a educação formal em seus investimentos públicos; mobilizam-se no sentido de conquistarem uma educação de qualidade que as credenciem para uma posição social desejada, entendendo os diplomas como certificados que lhes darão acesso a essas posições (SCHULTZ, 1973).

No entanto, alguns estudiosos têm questionado a relação direta entre aumento da escolarização e ascensão social, entendendo que origem social e destinos educacionais estão fortemente relacionados e que a escola não tem o efeito transformador que se esperaria em tais transições. Ao contrário, ela apenas reproduz a estratificação social existente, não agindo como garantidora de mobilidade (BOURDIEU, 1998). A maior parcela do sucesso ou fracasso escolar se deve ao background econômico e familiar, que irá influenciar até mesmo a motivação e as habilidades cognitivas dos estudantes (JENCKS, 2008).

Sem negar a relação existente entre origem social e destino educacional, outros estudiosos defendem que o efeito da escola na redução de desigualdades pode variar entre diferentes países e sistemas educacionais; que esse efeito não é uniforme entre as instituições, entre as redes de ensino e entre os países, considerando que as ações dos sujeitos históricos envolvidos no processo não são, obviamente, iguais (DUBET; DURU-BELLAT; VÉRÉTOUT, 2012). Diversos fatores podem influenciá-lo, como ações políticas do Estado ou de diversos grupos sociais, além de características das escolas e dos estudantes (RUTTER et al, 1979). Se a escola não tem se mostrado como um caminho certo para a 
mobilidade social, o contrário também parece ser determinístico demais, em que a escola apenas reproduz a estratificação existente do lado de fora de seus muros. A relação entre posição social e desigualdade educacional existe, porém, com diferentes medidas em diferentes realidades. O que é mais observável em países com grandes desigualdades, como no caso do Brasil (SILVA, 2003).

O país, nas últimas décadas, conseguiu ampliar a oferta de ensino formal, a partir da compreensão da educação como um direito social fundamental e da vinculação legal de receitas públicas aos investimentos em educação, com a redemocratização e a promulgação da Constituição Federal de 1988, associada às mudanças populacionais desse período. Como resultado, praticamente universalizou o ensino fundamental, com $98 \%$ da população entre 6 e 14 anos matriculada na escola (BRASIL, 2018).

Apesar disso, a escola brasileira não tem sido capaz de reduzir as disparidades existentes na sociedade. As taxas de analfabetismo, a trajetória irregular e o baixo aprendizado, além das desigualdades entre grupos sociais ou regiões territoriais são problemas ainda a serem resolvidos (ALVES; SOARES; XAVIER, 2016; CASTRO, 2009). A ampliação de vagas não tem resultado em uma maior igualdade de realização educacional, menos ainda se reflete em acesso a posições melhores na sociedade, persistindo a relação entre a origem social dos estudantes e a posição que ocuparão após a passagem pela escola, que só reduzem nos níveis mais avançados de ensino (BRITO, 2017).

Ainda assim, certas decisões escolares têm algum efeito sobre a redução das desigualdades entre os alunos. Se considerarmos que as oportunidades educacionais são o resultado da interação entre características dos indivíduos e contexto escolar, determinadas práticas escolares podem interferir no aprendizado. A Sociologia da Educação tem se dedicado também a essa interação, assumindo a existência do efeito-escola, ou seja, a capacidade de as escolas, em suas ações e políticas, influenciarem positivamente o desempenho escolar dos alunos. E que características intraescolares - infraestrutura, insumos, formação docente, organização das turmas, projeto pedagógico - podem fazer significativa diferença (BROOKE; SOARES, 2008). O efeito-escola, sem desconsiderar a influência da origem socioeconômica e cultural dos alunos no desempenho escolar, procura desvelar características das instituições e de seus profissionais que podem ser importantes para melhorar os resultados escolares. 


\section{PESQUISAS SOBRE ENTURMAÇÃO DOS ESTUDANTES}

Na perspectiva do efeito-escola, as formas de enturmação dos estudantes podem contribuir para reduzir ou ampliar diferenças de aprendizado entre eles. É o que tem demonstrado pesquisas que se dedicam a compreender esses efeitos, tanto no Brasil quanto no exterior.

Investigando as escolas públicas do Texas, na década de 1990, Hoxby (2000) chegou à conclusão de que existe um efeito dos pares dentro das classes, em que os estudantes com diferenças de desempenho interagem instruindo uns aos outros, influenciando de forma positiva o clima e a disciplina em sala de aula; e turmas heterogêneas estimulam essa interação.

Alves e Xavier (2017) pesquisaram possíveis associações entre fatores escolares e oportunidades de aprendizado em escolas públicas brasileiras. Os resultados indicam a existência de uma relação entre a formação de turmas com características homogêneas e a existência de professores sem formação adequada. Isto é, escolas com um maior número de professores sem licenciatura tendem a agrupar os estudantes, entre as turmas, por determinadas características. Além disso, as turmas homogêneas não estão associadas ao aumento das chances de aprendizado adequado. Estudo semelhante chegou à conclusão que o efeito das escolas é significativo justamente na forma como elas organizam os alunos em turmas. E que a disposição homogênea por níveis de habilidade não apenas prejudica o desempenho dos alunos, como também provoca um aumento nas diferenças entre eles, acirrando a estratificação escolar (ALVES; SOARES, 2007).

Gomes (2005) destaca que fatores intraescolares, como as formas de composição das turmas, têm mais efeito nos sistemas educacionais de países em desenvolvimento. Em países da América Latina (Brasil, Chile e Cuba), o efeito da turma explicou ainda mais os resultados dos alunos em testes, principalmente sob dois aspectos: o tamanho da turma e a sua heterogeneidade. Turmas heterogêneas - diferentes níveis de habilidade ou de características socioculturais - têm efeito positivo no desempenho e contribuem para a redução do hiato existente entre os alunos. Igualmente, Willms (1992) cita que o tamanho e as características das turmas podem influenciar o desempenho dos alunos. Suas pesquisas se referem também a currículos diferentes de Matemática em cada turma, o que parece ser intencional nas escolas. São decisões de gestores e professores que podem interferir na diferença entre alunos dentro de uma mesma instituição.

Os mecanismos de alocação entre os turnos de funcionamento da escola também podem influenciar os resultados escolares. Bartholo (2014), analisando a rede de ensino municipal do Rio de Janeiro, aponta a existência de um tracking informal dos alunos entre os turnos por sua situação de distorção idade-série. O 
que, à falta de uma legislação que regule ou estimule tal prática, parece ser uma ação deliberada de seleção dos estudantes. $\mathrm{O}$ autor questiona quais fundamentos pedagógicos justificam essa ação.

Lafontaine (2011) levanta limites para as pesquisas do que chama "efeito da sala de aula", como a carência de dados no nível de turmas, já que muitas avaliações em larga escala existem apenas no nível das escolas. Ainda assim, elas mostram que o efeito da sala de aula é igual ou maior do que o efeito da escola em sistemas de ensino de alguns países europeus. Se a escola faz diferença, o modo de organização das turmas pode fazer tanto ou mais.

As decisões sobre como agrupar os alunos em classes variam entre escolas, sistemas de ensino ou países. Mas estudos têm demonstrado, com o auxílio de metodologias mais adequadas de análise, que elas podem reduzir ou ampliar as desigualdades intraescolares.

\section{METODOLOGIA}

Nesta pesquisa, realizamos uma análise descritiva de dados provenientes dos questionários contextuais e do desempenho na Prova Brasil aplicada aos alunos do $9^{\circ}$ ano do ensino fundamental de escolas públicas do município de Contagem-MG, em 2015. Também utilizamos informações do Censo Escolar. Ambos são disponibilizados para download pelo Instituto Nacional de Estudos e Pesquisas Educacionais Anísio Teixeira (Inep). Para a escolha das escolas, consideramos dois critérios: a existência de $9^{\circ}$ ano na escola e sua oferta nos dois turnos - matutino e vespertino. Assim, foi construído um banco de dados com 6 escolas municipais e 1.030 estudantes.

Exploramos os questionários aplicados aos alunos, inicialmente a resposta a uma pergunta específica - "Você já foi reprovado?" -, cuja frequência de respostas serviu para calcular a proporção de repetentes por turno e por turma em cada escola. A questão permitiu três respostas diferentes: Não; Sim; Sim, duas vezes ou mais. Responderam já terem sido reprovados mais de uma vez aproximadamente 5\% do total de alunos. Entendemos que, numa possível criação de turmas dos repetentes, os "reprovados mais de uma vez" ficariam junto aos que foram reprovados apenas uma vez. Por isso, e para fins analíticos, somamos as respostas transformando-as apenas em "Não" e "Sim".

Analisamos perguntas relativas ao sexo e a como o indivíduo se considera (cor/raça), de forma a apreender uma possível divisão dos estudantes por essas características. Sobre a última pergunta, cabe uma explicação complementar: no questionário, cada aluno tinha como opções de respostas: Branco; Pardo; Preto; Amarelo; Indígena; Não sei. Novamente, para fins analíticos, as categorias Branco 
e Negro (a soma de pretos e pardos) permaneceram. Os que se declararam amarelo ou indígena foram, respectivamente, $2,8 \%$ e $1,5 \%$ e, por essa razão, desconsideramos na análise.

O trabalho incluiu o nível socioeconômico (NSE) dos alunos e sua relação com as turmas. O indicador de NSE utilizado foi baseado num construto estimado pelas respostas dos alunos a 24 itens do questionário contextual da Prova Brasil, relativos ao nível educacional e ocupação dos seus pais, e ao acesso a bens de consumo e serviços, conforme o modelo proposto por Alves, Soares e Xavier (2014). Esse índice foi agregado por turmas e dividido em quartis, de modo que o primeiro quartil informe o conjunto de alunos com menor NSE e, o quarto quartil, os alunos com maior NSE. A medida final utilizada é o percentual de alunos do primeiro quartil por turma, isto é, o percentual de alunos com menor NSE em cada turma.

O desempenho dos estudantes também foi considerado, explorando os resultados em Matemática, avaliados na Prova Brasil, que mede essa proficiência em quatro níveis: insuficiente, básico, proficiente e avançado (SOARES, 2009). Para a medida de desempenho aqui utilizada, calculamos o percentual de alunos com desempenho considerado insuficiente em cada turma. Quanto maior o percentual, pior é a proficiência da turma. Assim, foi possível comparar o desempenho em Matemática entre as turmas de uma mesma escola. É importante ressaltar que a proficiência tomada é de 2015 e não há uma medida anterior do desempenho dos alunos que possibilite averiguar a sua evolução, associada a alguma forma de segmentação entre turmas. Entretanto, assumimos que o desempenho atual está fortemente correlacionado ao desempenho prévio do aluno e, portanto, pode ser tomado como uma proxy.

A última pergunta avaliada, já no questionário aplicado aos diretores das escolas, foi sobre a formação das turmas: "Neste ano, qual foi o principal critério utilizado para a formação das turmas nesta escola?” A frequência das respostas, relacionadas à homogeneidade ou heterogeneidade dos grupos de alunos, permitiu observar que critérios as escolas parecem seguir na distribuição dos alunos entre turmas.

Agregamos todas as informações sobre os alunos por turma, já que interessa saber, em cada turma, a proporção de repetentes, de meninos e meninas, brancos e negros, com baixo NSE e com desempenho insuficiente que evidencie alguma estratificação. Por fim, comparamos os dados à questão sobre critérios para a formação de turmas, aplicada aos diretores. 


\section{RESULTADOS E DISCUSSÃO}

\section{Repetentes por turno}

A primeira análise investigou a possível existência de diferenças na distribuição dos estudantes repetentes entre turnos de funcionamento das escolas. A evidência é que parece não haver uma ação intencionada de estratificação por turnos. O Gráfico 1 mostra que o percentual de indivíduos que já foram reprovados em algum ano de escolaridade, no conjunto de alunos, aproxima-se do percentual dividido pelos turnos em que estudam. O eixo vertical do gráfico indica o percentual de estudantes já reprovados, enquanto o eixo horizontal indica os grupos em que esse percentual foi comparado: no total das escolas e em cada um dos turnos.

\section{Gráfico 1 - Reprovação por turno escolar}

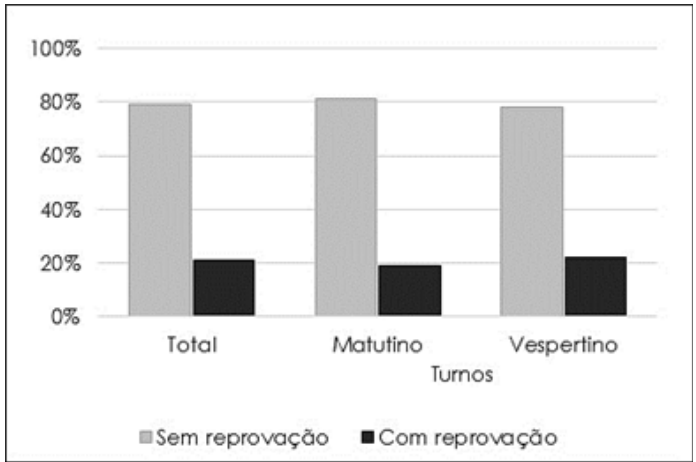

Fonte: Elaboração própria a partir de dados da Prova Brasil 2015.

O percentual de alunos que já foram reprovados, em todas as escolas, é de cerca de $20 \%$. Ao analisarmos pelos turnos em que estão matriculados, essa proporção permanece bem próxima. Realizamos, ainda, o teste estatístico pelo método do qui-quadrado, que verifica o grau de independência existente entre duas variáveis (STEVENSON, 2001), não encontrando uma associação entre a repetência e os turnos. Ou seja, os estudantes repetentes não são separados por turnos nas escolas pesquisadas. $O$ resultado não corrobora a pesquisa de Bartholo (2014), que demonstrou haver uma prática sistemática de alocação dos estudantes em defasagem idade-série por turnos, nas escolas públicas municipais do Rio de Janeiro. As diferenças de resultados, entretanto, podem ser atribuídas às próprias decisões pedagógicas de cada escola ou sistema, visto que não existe, 
em nenhuma das redes de ensino pesquisadas, uma normatização ou diretriz no sentido de realizar essa forma de alocação dos alunos entre os turnos, por qualquer característica.

\section{Repetentes por turmas}

Uma segunda análise procurou evidências de alguma forma de distribuição desigual dos estudantes repetentes entre as turmas de $9^{\circ}$ ano, em cada uma das escolas. O objetivo foi perceber se os estudantes que já foram reprovados acabam sendo agrupados em determinadas classes, enquanto os estudantes que nunca repetiram nenhum ano são agrupados em outras. Nesse caso, o critério dos turnos não é mais relevante, já que escolas com mais de uma turma apresentarão (ou não) essa divisão.

Os resultados do cruzamento (indivíduos que informaram reprovação e turmas em que são matriculados) mostram que há estratificação dos alunos pela característica repetência. A Figura 1 ilustra como cada escola distribui seus estudantes que já foram reprovados entre as turmas. O eixo horizontal de cada gráfico representa as turmas da escola e o eixo vertical indica o percentual de alunos já reprovados. A ordem das turmas, originalmente na base de dados do Inep, é aleatória (provavelmente, se deve à ordem com que foram cadastradas pela secretaria de cada escola no Censo Escolar). Optamos por reordená-las, partindo da turma com menos reprovados para a com mais reprovados, para que a observação da diferença de composição das turmas fique mais clara.

Figura 1 - Percentual de alunos que já foram reprovados, por turma, em cada escola
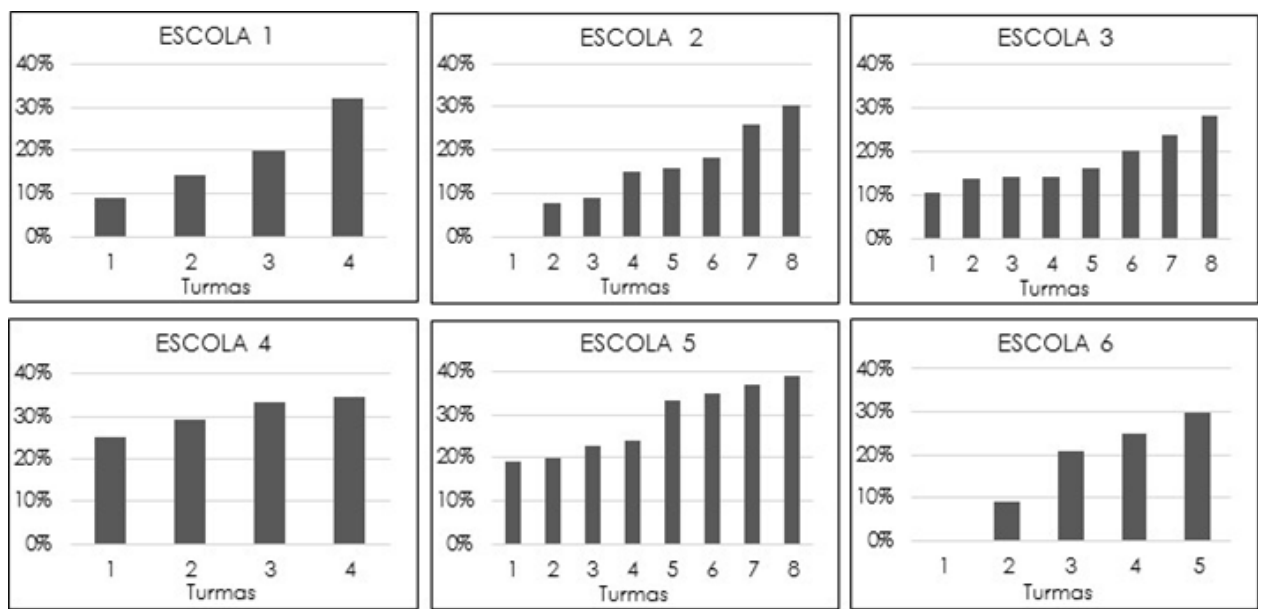

Fonte: Elaboração própria a partir de dados da Prova Brasil 2015. 
É possível perceber a existência de turmas com poucos estudantes que passaram pela reprovação, enquanto outras têm mais do que um terço de estudantes repetentes. Há escolas que mantiveram uma turma sem nenhum estudante repetente ( 2 e 6 ), mesmo que, no total de alunos dessas escolas, haja um número significativo de jovens em tal situação. A exceção é a Escola 4, que distribui de forma um pouco menos desigual os alunos repetentes, porém, tem um grande número de alunos nessa situação em todas as turmas. As diferenças percentuais de alunos com e sem reprovação, entre turmas de uma mesma escola, e no conjunto de escolas pesquisadas, fazem crer que há alguma forma de diferenciação dos alunos entre turmas, por essa característica.

\section{Sexo e cor/raça}

A investigação sobre a distribuição dos alunos por turmas também se deteve em duas características sociodemográficas: sexo e cor/raça. A intenção foi saber se nas turmas de uma mesma escola há uma diferença no número de indivíduos do sexo masculino e feminino, ou entre brancos e negros, como já foi observada entre os já reprovados. A Figura 2 traz a proporção de alunos por sexo e, a Figura 3, a proporção por cor/raça. Novamente, o eixo horizontal de cada gráfico representa as turmas e cada barra representa o total de alunos (100\%), com o percentual para cada característica. Os valores detalhados de alunos e escolas são descritos no Apêndice.

Figura 2 - Percentual de alunos por sexo, em cada turma, por escola
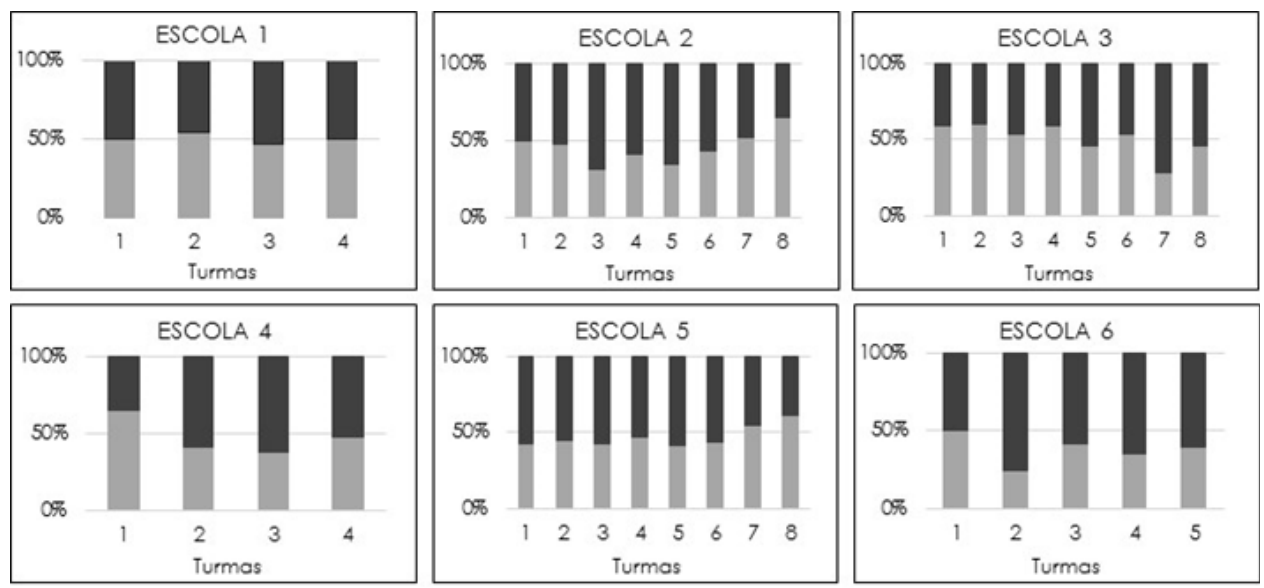

Masculino

Feminino

Fonte: Elaboração própria a partir de dados da Prova Brasil 2015. 
Em todas as escolas há um número total aproximadamente igual de alunos do sexo masculino e feminino. Pode-se até observar uma variação entre as turmas, mas o que aparentemente é aleatório e não configura uma situação de estratificação. A Escola 1, por exemplo, tem uma distribuição semelhante das turmas com relação ao sexo dos alunos. Já a Escola 2 tem uma variação maior entre as 8 turmas, mas não há um padrão: algumas turmas têm mais alunos do sexo masculino, outras menos. Entretanto, essa variação não parece acontecer por uma escolha intencional da escola. Vejamos a distribuição dos alunos por cor/ raça.

\section{Figura 3 - Percentual de alunos brancos e negros, em cada turma, por escola}
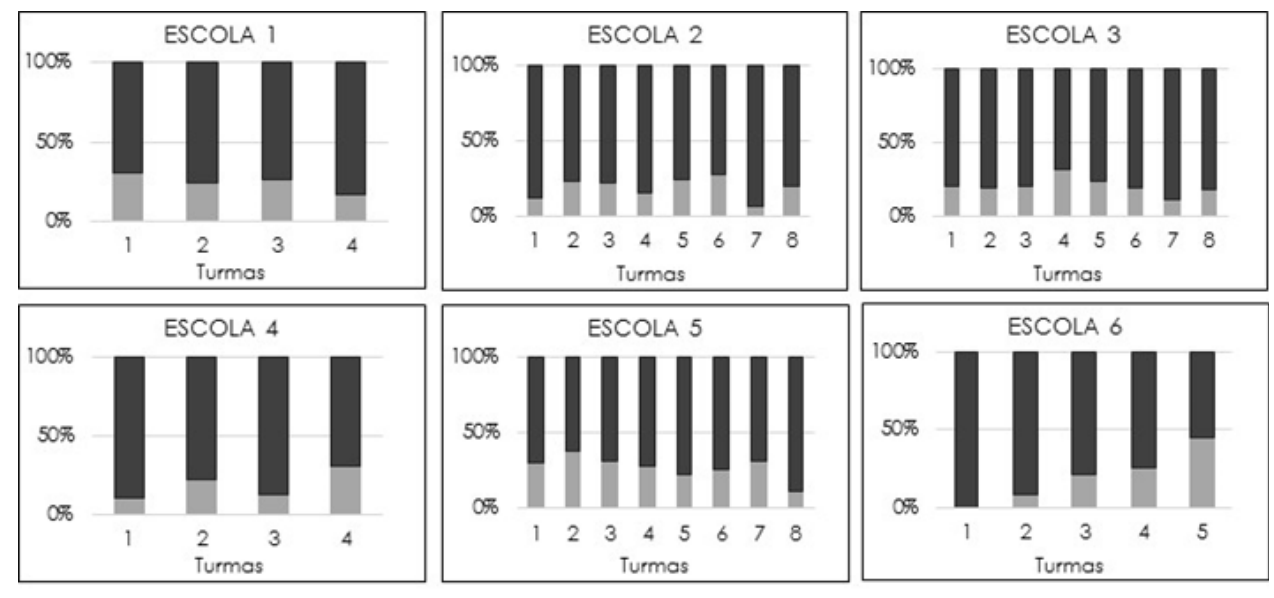

Fonte: Elaboração própria a partir de dados da Prova Brasil 2015.

Em todas as escolas, a distribuição dos alunos por cor/raça indicou mais negros do que de brancos. Importa registrar que, de acordo com a legislação municipal que trata do acesso às escolas, o único critério para a matrícula é o chamado zoneamento (CONTAGEM, 2015). Isso quer dizer que o aluno deve ser matriculado na escola mais próxima de sua residência, não importando nenhuma característica social. Então, se os estabelecimentos apresentam um número maior de alunos negros, espera-se que seja apenas reflexo da população e não uma política da escola. Pesquisas recentes sobre estratificação espacial, em grandes cidades brasileiras, apontam realidades semelhantes: bairros periféricos concentram um número maior de indivíduos negros, o que se reflete nas matrículas escolares e na distribuição racial entre as escolas (COSTA; BARTHOLO, 2014; MENDES, 
2017). Uma estratificação racial seria mais perceptível entre as escolas do município do que no interior delas, o que realmente não ocorre em nossa amostra de escolas. $\mathrm{O}$ arranjo dos alunos nas turmas parece casual, não estabelecendo um padrão.

\section{Nível socioeconômico}

A distribuição dos alunos por suas características socioeconômicas também é importante para entendermos a organização da escola e os seus resultados. Por isso, incluímos na análise o NSE dos alunos alocados por turmas, dentro das escolas, o que é apresentado na Figura 4. Dividindo-o em quartis, calculamos o percentual de jovens com menor NSE em cada turma, representado nos gráficos por barras. Quanto maior o valor da barra de cada turma, menor é o seu NSE, ou mais alunos com NSE baixo ela possui. A ordem das turmas em cada escola se manteve a mesma da análise por repetentes.

\section{Figura 4 - Percentual de alunos no primeiro quartil de NSE, em cada turma, por escola}
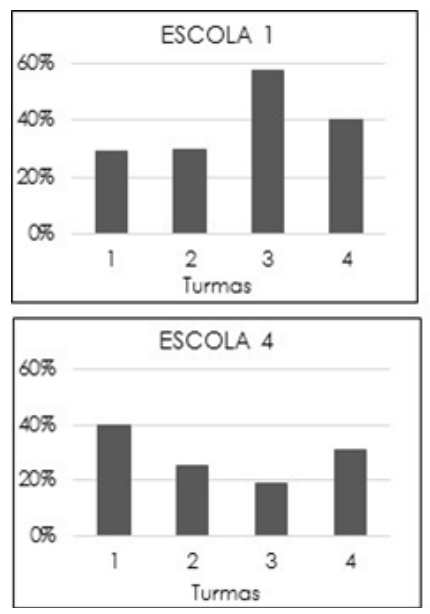
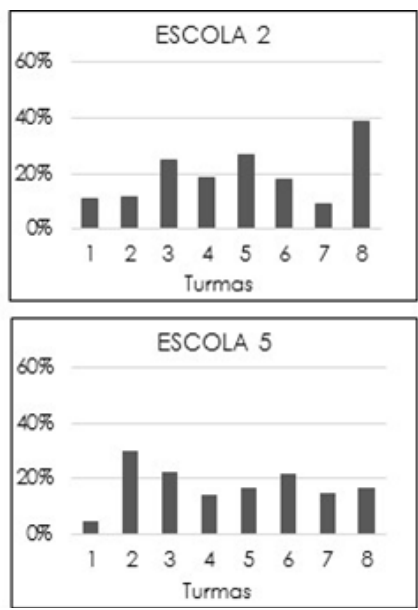
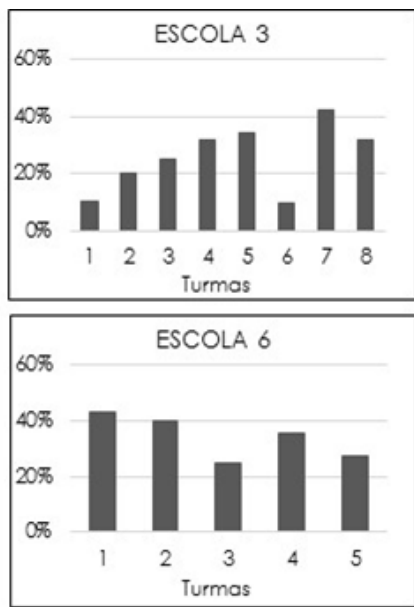

Fonte: Elaboração própria a partir de dados da Prova Brasil 2015.

Conseguimos ver contrastes entre os percentuais de alunos com baixo nível socioeconômico entre turmas de uma mesma escola, mesmo que não haja um padrão na disposição dos alunos pelo NSE. Ou seja, existe diferença de NSE entre turmas. Por exemplo, a Escola 1 possui apenas uma turma com quase $60 \%$ de alunos com baixo NSE, enquanto as outras têm, no máximo, 40\% de alunos nessa situação. Já a Escola 3 possui duas turmas que registram 10\% de alunos com baixo NSE, enquanto uma turma concentra mais de $40 \%$ dos alunos assim. 
O que não quer dizer que haja intencionalmente a distribuição dos alunos pela sua realidade social (até porque não sabemos se as escolas têm acesso a informações sociais dos estudantes). É importante observar, ainda, que não há associação entre alunos repetentes e com baixo NSE, comparando as Figuras 1 e 4. A Escola 6 possui uma turma sem nenhum aluno repetente, que, no entanto, é a turma com a maior proporção de baixo NSE. O contrário também ocorre: turmas com maior nível socioeconômico e que possuem mais alunos já reprovados, como na Escola 5.

Para Alves e Soares (2008), existe uma heterogeneidade no nível socioeconômico entre as escolas, mas também entre os alunos dentro de uma mesma escola. E fatores sociais estão mais relacionados aos resultados escolares nos anos iniciais, reduzindo ao longo das etapas de estudo. O que contribui para explicar a não existência de uma relação entre o percentual de alunos repetentes e o baixo NSE em turmas de $9^{\circ}$ ano. Além disso, tais resultados concordam com o que a Sociologia da Educação tem demonstrado: a realidade socioeconômica tem importante influência nos resultados escolares, mas as escolas também conseguem produzir um relativo efeito sobre o desempenho e a trajetória dos estudantes, sobretudo em realidades desiguais (ANDRADE; SOARES, 2008).

\section{Desempenho}

Examinamos, ainda, uma possível desigualdade entre turmas pelo desempenho escolar, assumindo que o desempenho do ano em estudo é relacionado com o rendimento anterior: se os alunos foram enturmados de acordo com esses resultados, as diferenças de desempenho atuais devem ajudar a visualizar alguma forma de estratificação. A medida de desempenho utilizada foi a proficiência em Matemática. A Figura 5 considera, nas barras, o percentual de alunos com desempenho insuficiente: quanto maior, mais alunos com baixo desempenho na turma. Novamente, manteve-se a ordem das turmas, nas escolas, pelo número de alunos repetentes. 
Figura 5 - Percentual de alunos com desempenho insuficiente em Matemática, em cada turma, por escola
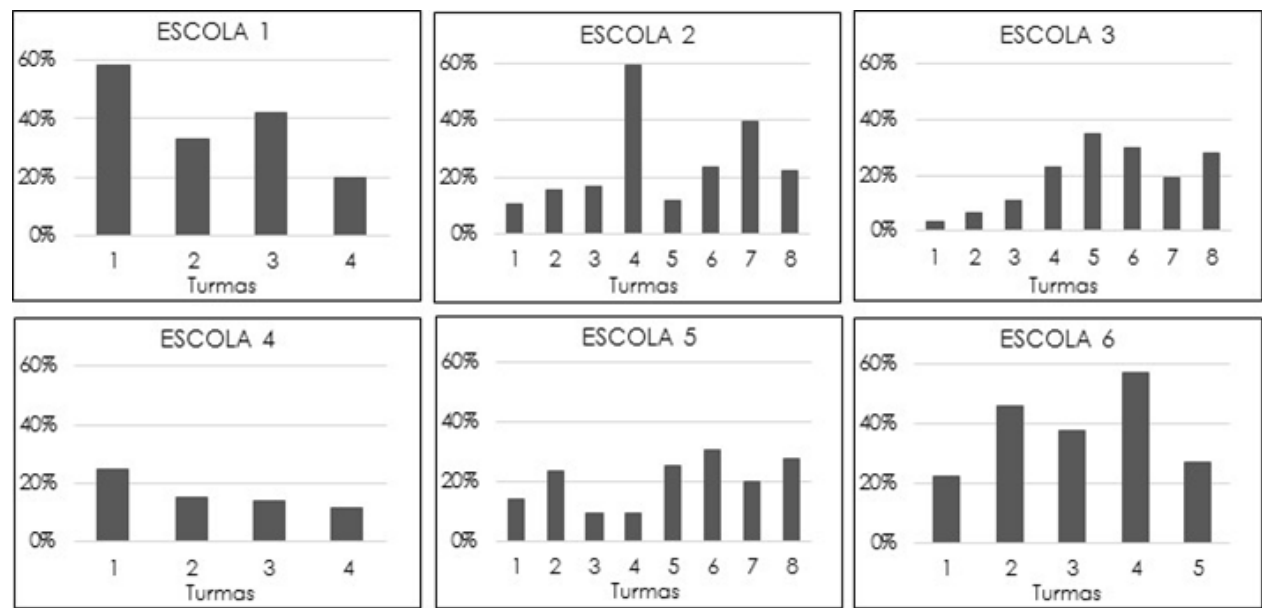

Fonte: Elaboração própria a partir de dados da Prova Brasil 2015.

Há estudantes com diferentes níveis de desempenho em Matemática e que não estão distribuídos de forma equitativa entre as turmas, o que sugere razoável diferença no número de alunos por essa característica. A Escola 1, por exemplo, reúne quase $60 \%$ de alunos com desempenho insuficiente na Turma 1 , ao passo que a Turma 4 tem apenas $20 \%$ dos alunos assim. A Escola 2 apresenta uma turma (4) com mais do que o dobro de alunos insuficientes que as outras. De forma diferente, a Escola 4 não demonstra grande variação na distribuição dos alunos insuficientes em suas turmas. Porém, é uma escola em que boa parte dos alunos têm bom desempenho.

Comparando os resultados da Figura 1 e da Figura 5, não há relação entre o percentual de alunos repetentes e com baixo desempenho. Há turmas com muitos já reprovados que têm bom desempenho em Matemática (por exemplo, a Turma 5 - Escola 6); e turmas com poucos repetentes, mas com maior proporção de desempenho insuficiente (Turma 1 - Escola 1).

Uma hipótese para entender essa condição é o uso de outros critérios avaliativos, além do aprendizado, ao reprovar os alunos: questões como comportamento e mérito também são usualmente considerados, nas avaliações, pelos professores (GLÓRIA; MAFRA, 2004; RIBEIRO et al, 2018). Crahay e Marcoux (2010) apontam que, para alguns professores, o desempenho acadêmico dos alunos não é determinante na decisão pela reprovação, envolvendo também a dedicação às atividades ou obediência às regras institucionais. As trajetórias 
escolares se dissociam do aprendizado dos conteúdos e alunos com diferentes níveis de desempenho podem ser reprovados. Precisaríamos, porém, de um estudo mais aprofundado nas escolas de Contagem para afirmar isso.

\section{Critérios para a formação das turmas}

Por último, comparamos as repostas para a pergunta "Neste ano, qual foi o principal critério utilizado para a formação das turmas nesta escola?", ao percentual de estudantes já reprovados, por turma e por escola, descrito anteriormente. Como já foi citado, essa questão fez parte do questionário aplicado ao diretor de cada escola. A Tabela 1 exibe as opções de respostas sobre idade ou rendimento dos alunos. Na tabela, as escolas estão identificadas por siglas (E1, E2...) e o X se refere ao item que o diretor daquela escola respondeu. O objetivo da comparação foi identificar alguma relação entre as características dos estudantes, aqui investigadas, e as formas de organização das turmas, de acordo com as respostas dos diretores.

\section{Tabela 1 - Neste ano, qual foi o principal critério utilizado para a formação das turmas nesta escola?}

\begin{tabular}{lccccccc}
\hline & \multicolumn{1}{c}{ Escolas } & & \\
& E1 & E2 & E3 & E4 & E5 & E6 \\
\hline Homogeneidade quanto à idade (ahunos com a mesma idade) & & & $\mathrm{X}$ & & $\mathrm{X}$ & \\
\hline $\begin{array}{l}\text { Homogeneidade quanto ao rendimento escolar (ahmos com } \\
\text { rendimento similar) }\end{array}$ & $\mathrm{X}$ & $\mathrm{X}$ & & & & $\mathrm{X}$ \\
\hline
\end{tabular}

Heterogeneidade quanto à idade (alunos com idades diferentes)

Heterogeneidade quanto ao rend imento escolar (alunos com $\quad \mathrm{X}$ rendimentos diferentes)

Fonte: Elaboração própria a partir de dados da Prova Brasil 2015.

A maior parte das respostas sobre o critério de formação das turmas tem a ver com a homogeneidade dos alunos, seja quando à idade ou quanto ao rendimento: as escolas parecem optar por turmas homogêneas em termos de idade/rendimento, mesmo que se criem turmas bastante diferentes entre si. A exceção, novamente, foi a Escola 4, cujo diretor respondeu que o principal critério utilizado na instituição foi a heterogeneidade do rendimento dos alunos, misturando alunos com diferentes níveis de aprendizado em uma mesma turma. Parece haver, no restante das escolas, uma intencionalidade na distribuição desigual 
de indivíduos que já repetiram algum ano entre as turmas, formando turmas homogêneas. A questão que se coloca é entender se essa decisão é motivada por uma suposta melhoria do aprendizado.

Pesquisas recentes sobre a formação de turmas no Brasil (ALVES, 2007; BARBOZA, 2006) discutem se a estratificação dos alunos por alguma característica individual será benéfica ou prejudicial em termos de aprendizado. Alguns docentes defendem a enturmação dos alunos por desempenho acadêmico como uma medida que facilita o planejamento pedagógico, já que os professores poderão trabalhar os conteúdos com diferentes níveis de dificuldade, inclusive assumindo turmas mais "fáceis" ou mais "difíceis", de acordo com o perfil, a formação e a experiência de cada um. Nesse ponto, Bernardo (2010) afirma que a distribuição desigual do conhecimento entre as turmas pode criar uma situação de aprendizado excelente para alguns poucos alunos e insuficiente para o restante, indo contra as intenções de equidade na qualidade da educação.

A sociabilização dos estudantes de uma mesma turma também deve ser levada em consideração: Alves (2007) explica que a interação intelectual entre os alunos com diferentes níveis, bem como o ambiente contextual de uma classe heterogênea podem se refletir em ganhos de aprendizado. De forma oposta, as decisões sobre a distribuição dos estudantes entre as turmas podem fazer com que pequenas diferenças de desempenho se transformem em grandes diferenças entre os grupos de alunos, estimulando a estratificação nas escolas.

Outro aspecto que merece destaque é o da construção de uma expectativa de aprendizado e de futuro que essa divisão pode trazer para os alunos. Escolas e turmas homogêneas podem influenciar os estudantes nelas matriculados, no sentido de que os baixos desempenhos passam a ser "naturalizados" pelos estudantes como se fossem inerentes às suas situações, sejam socioeconômicas ou cognitivas (COSTA, 2008), ampliando ainda mais a estratificação dentro das escolas e entre elas.

As formas de enturmação dos alunos, verificadas em nossa amostra de escolas, não encontram justificativa em termos de resultados educacionais. É importante, no entanto, que se ressalte o limite da pesquisa. Ao analisarmos dados de uma amostra com poucos alunos, seja em cada escola ou em cada turma, pequenas variações na quantidade de indivíduos podem se refletir em relativas diferenças nos percentuais apresentadas no trabalho. Por isso, os resultados não podem ser generalizados. Ainda assim, a realidade aqui encontrada não deve ser negligenciada e estudos futuros podem se dedicar a métodos que corrijam as medidas para pequenas populações. 


\section{CONSIDERAÇÕES FINAIS}

A análise da alocação de estudantes por turno e turma demonstrou haver formas de organização dos indivíduos com uma característica especial: eles já terem sido reprovados em algum ano da trajetória escolar. Dessa forma, pôde-se perceber, dentro de uma mesma escola, e no mesmo ano de escolaridade, desde turmas sem reprovados, com poucos ou com muitos alunos que já repetiram algum ano. Outras características sociais dos indivíduos, como sexo e cor/ raça, não apresentaram padrões de alocação dentro de turmas que insinuem ser consequência de estratificação.

Com relação à medida de nível socioeconômico e de desempenho em Matemática, constatamos uma relativa diferença nos percentuais entre as turmas dentro de cada escola, ou seja, alguma forma de estratificar os alunos. Os dados não nos permitem saber se as diferenças entre turmas, por essas características, são intencionais ou aleatórias. No entanto, não há qualquer associação entre o percentual de repetentes, (1) o percentual de menor NSE e (2) o percentual de estudantes com desempenho insuficiente. Isso sugere que não exista forte relação (1) entre a reprovação e a realidade social dos alunos e (2) entre a reprovação e o aprendizado dos conteúdos escolares. O cruzamento das informações também demonstrou que, aparentemente, há uma decisão consciente da gestão das escolas em agrupar os estudantes pela idade ou pelo desempenho escolar.

As pesquisas mais recentes sobre o tema têm relatado mais prejuízos do que vantagens, em termos de qualidade na educação, ao se distribuir homogeneamente os estudantes. E parte da literatura sobre estratificação social contesta os efeitos da educação formal como meio de mobilidade social e redução das desigualdades justamente pelo aspecto classificatório das escolas, que apenas refletem a estratificação existente na sociedade. Procedimentos que diferenciem a composição das turmas por alguma característica social ou de desempenho dos estudantes podem levar a aumentar as desigualdades entre os alunos no futuro. Nesse aspecto, a reflexão sobre as formas de estratificação que a escola promove pode servir para que as escolas, de fato, mostrem-se como caminho de redução das desigualdades sociais. Isso porque, entre os diversos fatores relacionados à eficácia das escolas, a formação das turmas é uma decisão que pode ser controlada pelos gestores e educadores nas escolas. 


\section{REFERÊNCIAS}

ALVES, Maria Teresa Gonzaga; SOARES, José Francisco. Efeito-escola e estratificação escolar: o impacto da composição de turmas por nível de habilidade dos alunos. Educação e Revista. Belo Horizonte, n. 45, p. 25-59, 2007.

ALVES, Maria Teresa Gonzaga; SOARES, José Francisco. O efeito das escolas no aprendizado dos alunos: um estudo com dados longitudinais no ensino fundamental. Educação e Pesquisa. São Paulo, v.34, n.3, p. 527-544, 2008.

ALVES, Maria Teresa Gonzaga; SOARES, José Francisco; XAVIER, Flavia Pereira. Desigualdades educacionais no ensino fundamental de 2005 a 2013: hiato entre grupos sociais. Revista Brasileira de Sociologia, v. 4, n. 7, 2016.

ALVES, Maria Teresa Gonzaga et al. Desigualdades de aprendizado entre alunos das escolas públicas brasileiras: evidências da Prova Brasil (2007 a 2013). Debates ED, n. 5, p. 1-116, 2017.

ANDRADE, Renato Judice; SOARES, José Francisco. O efeito da escola brasileira. Estudos em Avaliação Educacional. São Paulo, v. 19, n. 41, p. 379406, 2008.

BARBOZA, Eleuza Maria Rodrigues. A composição das turmas e o desempenho escolar na rede pública de ensino de Minas Gerais. Coleção Digital PUC-RIO. Rio de Janeiro, set. 2006.

BARTHOLO, Tiago Lisboa; COSTA, Marcio da. Turnos e segregação escolar: discutindo as desigualdades intraescolares. Cadernos de Pesquisas. São Paulo, v. 44, n. 153, 2014.

BERNARDO, Elisângela da Silva. Organização de turmas e práticas de gestão escolar: a aprendizagem em leitura dos alunos das escolas públicas cariocas. Revista Educação e Cultura Contemporânea. Rio de Janeiro: UNESA, v. 7, n. 14, p. 101-121, jan./jun. 2010.

BOURDIEU, Pierre. A Escola conservadora: as desigualdades frente à escola e à cultura. In: NOGUEIRA, Maria Alice; CATANI, Afrânio (org.). Escritos de Educação. Petrópolis: Vozes, 1998. p. 39-64. 
BRASIL. Sinopse Estatística da Educação Básica 2017. Brasília: Inep, 2018.

BRITO, Murillo Maschner Alves de. Novas tendências ou velhas persistências? Modernização e expansão educacional no Brasil. Caderno de Pesquisas. São Paulo, v. 47, n. 163, p. 224-263, mar. 2017.

CASTRO, Jorge Abrahão de. Evolução e desigualdade na educação brasileira. Educação e Sociedade, v. 30, p. 673-697, 2009.

CHUDGAR, Amita; LUSCHEI, Thomas. National income, income inequality, and the importance of schools: a hierarchical cross-national comparison. American Educational Research Journal, v. 46, n. 3, p. 626-658, 2009.

CONTAGEM. Secretaria Municipal de Educação. Resolução no 003/2015. Dispõe sobre o acesso e a permanência do estudante no Ensino Fundamental Regular nas Escolas Municipais de Contagem para o ano 2017. 2015.

CORREA, Erisson Viana; BONAMINO, Alicia; SOARES, Tufi Machado. Evidências do efeito da repetência nos primeiros anos escolares. Estudos em Avaliação Educacional. São Paulo, v. 25, n. 59, p. 242-269, set./dez. 2014.

CORTEZÃO, Luísa. O arco-íris na sala de aula? Processos de organização de turmas: reflexões críticas. Cadernos de organização e administração educacional, n. 1, p. 1-15, 2007.

COSTA, Marcio da; KOSLINSKI, Mariane. Prestígio escolar e composição de turmas: explorando a hierarquia em redes escolares. Estudos em Avaliação Educacional, v. 19, n. 40, p. 305-330, maio/ago. 2008.

COSTA, Marcio da; BARTHOLO, Tiago Lisboa. Padrões de Segregação Escolar no Brasil: um estudo comparativo entre capitais do país. Educação e Sociedade. Campinas, v. 35, n. 129, p. 1183-1203, out./dez. 2014.

CRAHAY, Marcel; MARCOUX, Géry. Comment et pourquoi les enseignants décident du redoublement de certains élèves? Genève, Suisse: Fonds national Suisse de la Recherche, 2010. 
DAVIS, Kingsley; MOORE, Wilbert. Alguns princípios de estratificação. In: BERTELLI, A. R.; PALMEIRA, M. G. S.; VELHO, O. G. C. A. (org.). Estrutura de classes e estratificação social. São Paulo: Zahar Ed., 1969.

DUBET, François; DURU-BELLAT; Marie; VÉRÉTOUT, Antoine. As desigualdades escolares antes e depois da escola: organização escolar e influência dos diplomas. Sociologias. Porto Alegre, ano 14, n. 29, jan./abr. 2012, p. 22-70.

GOMES, Candido Alberto. A escola de qualidade para todos: abrindo as camadas da cebola. Ensaio: Avaliação e Políticas Públicas em Educação. Rio de Janeiro, v. 13, n. 48, p. 281-306, 2005.

GLÓRIA, Dília Maria de Andrade; MAFRA, Leila de Alvarenga. A prática da não retenção na narrativa de professores do ensino fundamental: dificuldades e avanços na busca do sucesso escolar. Cadernos de Educação e Pesquisa. São Paulo, v. 30, n. 2, p. 231-250, maio/ago. 2004.

GRUSKY, David. Social Stratification: class, race, and gender in sociological perspective. 4a edição. Colorado: Westview Press, 2014.

HALLER, Archibald. A estrutura da teoria da estratificação. In: HALLER, Archibald et al. (org.). O sistema de estratificação social brasileiro: pensando sistematicamente como a desigualdade funciona. Belo Horizonte: Fino Traço, 2014. p. 25-33.

HOXBY, Caroline. Peer effects in the classroom: learning from gender and race variation. NBER Working Paper, n. 7867, 2000.

JENKS, Christopher. Desigualdade no aproveitamento educacional. In: BROOKE, Nigel; SOARES, José Francisco (org.). Pesquisa em eficácia escolar: origem e trajetórias. Belo Horizonte: Editora UFMG, 2008. p.50-66.

LAFONTAINE, Dominique. Efeito sala de aula (efeito turma). In: VAN ZANTEN, Agnez (coord.). Dicionário de educação. Petrópolis: Vozes, 2011. p. 279-284.

RIBEIRO, Vanda Mendes et al. Crença de professores sobre reprovação escolar. Educação em Revista, v. 34, 2018. 
RUTTER, Michael et al. Fifteen thousand hours: secondary schools and their effects on children. London: Open Books, 1979.

SCHULTZ, Theodore. Investimento em Capital Humano. In: SCHULTZ, Theodore. O Capital Humano: investimentos em educação e pesquisa. Rio de Janeiro: Zahar, 1973. p. 31-52.

SILVA, Nelson do Valle. Expansão escolar e estratificação educacional no Brasil. In: HASENBALG, Carlos; SILVA, Nelson do Valle. Origens e destinos: desigualdades sociais ao longo da vida. Rio de Janeiro: Topbooks, 2003.

SOARES, José Francisco. Índice de desenvolvimento da educação de São Paulo (Idesp). São Paulo em Perspectiva, v. 23, n. 1, p. 29-41, 2009.

SOARES, José Francisco; DELGADO, Victor Maia Senna. Medida das desigualdades de aprendizado entre estudantes de ensino fundamental. Estudos em Avaliação Educacional. São Paulo, v. 27, n. 66, 2016.

STEVENSON, William. Estatística Aplicada à Administração. São Paulo: Harbra, 2001.

WILLMS, John Douglas. Monitoring school performance: a guide for educators. London: Falmer Press, 1992. 


\section{APÊNDICE. DISTRIBUIÇÃO DAS VARIÁVEIS POR ESCOLAS, TURNOS E TURMAS}

\begin{tabular}{|c|c|c|c|c|c|c|c|c|c|c|c|c|}
\hline \multicolumn{4}{|c|}{ Escola } & \multirow{2}{*}{ 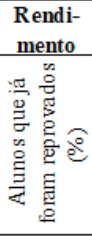 } & \multicolumn{3}{|c|}{ Sexo } & \multicolumn{3}{|c|}{ Cor/raça } & \multirow[b]{2}{*}{ 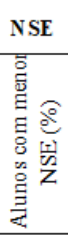 } & \multirow{2}{*}{ 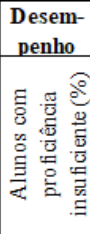 } \\
\hline & $\underset{\Xi}{\stackrel{\Xi}{\Xi}}$ & $\stackrel{\stackrel{P}{\Xi}}{\Xi}$ & 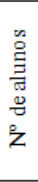 & & 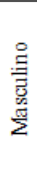 & 弯 & 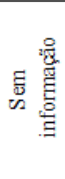 & $\stackrel{8}{\stackrel{0}{0}}$ & $\begin{array}{l}\text { O. } \\
\text { D. } \\
\text { Z }\end{array}$ & 壳 & & \\
\hline \multirow{4}{*}{ 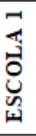 } & 1 & 1 & 26 & 11,5 & 12 & 10 & 4 & 4 & 17 & 5 & 57,7 & 42,3 \\
\hline & 2 & 2 & 33 & 13,0 & 9 & 9 & 15 & 3 & 15 & 15 & 29,2 & 58,3 \\
\hline & 3 & 2 & 26 & 20,0 & 13 & 13 & 7 & 6 & 17 & 10 & 40,0 & 20 \\
\hline & 4 & 2 & 30 & 31,6 & 9 & 10 & 11 & 5 & 14 & 11 & 30,0 & 33,3 \\
\hline \multirow{8}{*}{ 水 } & 1 & 1 & 26 & 00,0 & 9 & 17 & 0 & 6 & 19 & 1 & 11,1 & 10,5 \\
\hline & 2 & 1 & 26 & 07,7 & 9 & 9 & 8 & 2 & 15 & 9 & 11,5 & 15,4 \\
\hline & 3 & 1 & 29 & 08,3 & 12 & 13 & 4 & 5 & 19 & 5 & 25 & 16,7 \\
\hline & 4 & 1 & 29 & 14,3 & 12 & 11 & 6 & 1 & 17 & 11 & 18,2 & 59,1 \\
\hline & 5 & 2 & 27 & 15,4 & 7 & 15 & 5 & 4 & 15 & 8 & 26,9 & 11,5 \\
\hline & 6 & 2 & 29 & 17,6 & 11 & 6 & 12 & 3 & 12 & 14 & 17,6 & 23,5 \\
\hline & 7 & 2 & 26 & 26,1 & 7 & 9 & 10 & 3 & 8 & 15 & 8,7 & 39,1 \\
\hline & 8 & 2 & 27 & 29,4 & 9 & 13 & 5 & 3 & 17 & 7 & 38,9 & 22,2 \\
\hline \multirow{8}{*}{ 晃 } & 1 & 1 & 36 & 10,7 & 16 & 11 & 9 & 5 & 23 & 8 & 10,3 & 3,4 \\
\hline & 2 & 1 & 34 & 13,8 & 18 & 12 & 4 & 5 & 21 & 8 & 20 & 6,3 \\
\hline & 3 & 1 & 33 & 14,3 & 15 & 13 & 5 & 5 & 23 & 5 & 25 & 10,7 \\
\hline & 4 & 2 & 28 & 14,3 & 13 & 9 & 6 & 6 & 14 & 8 & 31,8 & 22,7 \\
\hline & 5 & 2 & 29 & 16,0 & 12 & 14 & 3 & 6 & 19 & 4 & 34,6 & 34,6 \\
\hline & 6 & 1 & 34 & 20,0 & 16 & 14 & 4 & 5 & 23 & 6 & 10 & 30 \\
\hline & 7 & 2 & 28 & 23,5 & 6 & 15 & 7 & 2 & 18 & 8 & 42,1 & 19 \\
\hline & 8 & 2 & 31 & 28,0 & 11 & 13 & 7 & 4 & 20 & 7 & 32 & 28 \\
\hline \multirow{4}{*}{ 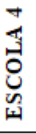 } & 1 & 2 & 28 & 25,0 & 13 & 7 & 8 & 2 & 18 & 8 & 40 & 25 \\
\hline & 2 & 1 & 30 & 29,2 & 10 & 14 & 6 & 5 & 18 & 7 & 25 & 15,4 \\
\hline & 3 & 2 & 25 & 33,3 & 8 & 13 & 4 & 2 & 19 & 4 & 19 & 14,3 \\
\hline & 4 & 1 & 33 & 34,6 & 11 & 12 & 10 & 8 & 18 & 7 & 30,8 & 11,5 \\
\hline \multirow{8}{*}{ 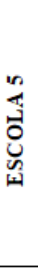 } & 1 & 1 & 27 & 19,0 & 9 & 12 & 6 & 6 & 14 & 7 & 4,8 & 14,3 \\
\hline & 2 & 1 & 29 & 20,0 & 8 & 10 & 11 & 6 & 11 & 12 & 30 & 23,8 \\
\hline & 3 & 1 & 29 & 22,7 & 9 & 12 & 8 & 5 & 13 & 11 & 22,7 & 9,1 \\
\hline & 4 & 2 & 26 & 23,8 & 9 & 10 & 7 & 5 & 13 & 8 & 14,3 & 9,5 \\
\hline & 5 & 2 & 28 & 33,3 & 10 & 14 & 4 & 4 & 15 & 9 & 16,7 & 25 \\
\hline & 6 & 2 & 28 & 34,8 & 10 & 13 & 5 & 5 & 16 & 7 & 21,7 & 30,4 \\
\hline & 7 & 1 & 27 & 36,8 & 11 & 9 & 7 & 6 & 14 & 7 & 15 & 20 \\
\hline & 8 & 1 & 25 & 38,9 & 11 & 7 & 7 & 2 & 16 & 7 & 16,7 & 27,8 \\
\hline \multirow{5}{*}{ 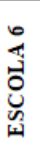 } & 1 & 1 & 18 & 00,0 & 7 & 7 & 4 & 7 & 5 & 6 & 42,9 & 22,2 \\
\hline & 2 & 2 & 20 & 09,1 & 3 & 9 & 8 & 1 & 11 & 8 & 40 & 46,2 \\
\hline & 3 & 1 & 29 & 20,8 & 10 & 14 & 5 & 4 & 17 & 8 & 25 & 37,5 \\
\hline & 4 & 2 & 17 & 25,0 & 5 & 9 & 3 & 3 & 9 & 5 & 35,7 & 57,1 \\
\hline & 5 & 2 & 17 & 30,0 & 4 & 6 & 7 & 4 & 6 & 7 & 27,3 & 27,3 \\
\hline
\end{tabular}

Fonte: Elaboração própria a partir de dados da Prova Brasil 2015. 


\section{Frederico Alves Almeida}

Mestre em Educação pela UFMG e doutorando na mesma instituição. Participa do Núcleo de Pesquisa em Desigualdades Escolares/UFMG. E-mail: fredericoalves@ufmg.br

\section{Flavia Pereira Xavier}

Doutora em Sociologia. Professora da Faculdade de Educação da UFMG e do Programa de Pós-graduação em Educação: conhecimento e inclusão social. Pesquisadora do Núcleo de Pesquisas em Desigualdades Escolares/UFMG. E-mail: flaviapx@ufmg.br

Recebido em: 15/07/2020

Aceito em: 07/08/2020 